\title{
Technologies of tutorial assistance in the visual activity distance education for the bachelors- designers
}

\author{
Natalia Zakharova ${ }^{1, *}$, Irina Vlasova $^{1}$, Olga Kartavtseva $^{2}$ \\ ${ }^{1}$ Don State Technical University, 1, Gagarin sq., 344010, Rostov-on-Don, Russia \\ ${ }^{2}$ Southern Federal University, 105, B. Sadovaya Str., 344000, Rostov-on-Don, Russia
}

\begin{abstract}
The article discusses the innovative approaches in the distance form of training the bachelors-designers, the direction of the tutorial assistance vector and the ways of realizing the creative potential of students in visual activity. Emphasis is placed on the innovative approaches and technologies in distant training the bachelors-designers, on the extracurricular activities of the students using telecommunications and information technologies, the tutoring technology as the most acceptable technology and a humane form of pedagogical interaction, creating the conditions for self-development and self-realization of students. The assessment criteria are defined as the products of visual activity in the process of distant training, and the products of art as a result of this activity. The conditions for successful self-realization and harmonization of the students in the visual activity distant training process.
\end{abstract}

\section{Introduction}

The ongoing modernization of higher professional education, in accordance with the Strategy for Innovative Development of the Russian Federation for the period until 2020, can be identified in the context of modern art education, forming it as intensive, additional, continuous. It should be noted that in innovative educational projects, for example, such as the national project "Education", which implementation is designed for 2019-2024, again the main task remains - the education of a harmoniously developed personality. [1] The solution of all the tasks assigned to higher education has intensified the epidemiological situation in the country. The introduction of the "tutorial position of a teacher" concept is being updated, in which pedagogical interaction and the organization of the learning process are formed taking into account the individual educational route. [2] A tutor accompanies a given educational route with maximum consideration for the needs and capabilities of the students. The approaches become innovative in education: technological, modular, competence, design, system, activity, environmental, existential.

The above-mentioned innovative approaches in distant training are caused by the need of modern society, in the development of which the main role is played by the individuals capable of innovation. At the same time, there is a change in the qualitative characteristics

\footnotetext{
*Corresponding author: Natalya.zaharova@gmail
} 
of the individuals' consciousness who are in education. It is noted that "on the one hand, intensive learning is a vital conscious social and didactic need, on the other hand, the evolutionary state of human consciousness is characterized by the certain cognitive processes' intensification, which makes it possible to make learning an intensive educational process of a new quality".

\section{Innovative approaches and technologies in the bachelor- designers' distant training}

1. The personality-oriented approach in distant training is implemented in the technologies of personality development (self-development), and in particular the development of abilities, without which the formation of competencies is impossible. A prerequisite for successful learning in distant training is the creation of a favorable adaptive developing environment that ensures the integration of students in electronic educational space and their personal self-realization.

2. The competency-based approach to distant training explains many professional situations in which the potentially existing abilities of a person should be developed and manifest themselves in the activity products. The leading role of theoretical knowledge, which often remained unclaimed, is replaced by the importance of personal experience and training is becoming more and more practical - oriented.

3. The technological approach in distant training has given freedom to the teacher's creativity - tutor (moderator). Pedagogical technologies allowed the tutor to go beyond the framework of teaching methods and enrich the learning process through the electronic information and educational environment. Extracurricular work of students is carried out using telecommunication and information technologies. To carry out the laboratory work, students use wired and wireless communication tools: the Internet, the DSTU electronic information and educational environment, email and social networks, smartphones, iPhones, tablets, as well as the specialized professional sites. Learning technologies are copyrighted, and they are created through an empirical approach. The concept of technology is the philosophical methodological position of the author. An individual worldview provides the author with an opportunity to create an individual pedagogical information space.

Distant training technology is a system category, the structural components of which are: goals, content, means of pedagogical interaction, organization of the learning process, a tutor - a student, an educational product as a result of activity. A characteristic feature of the technology is the distance participation of students in the educational process. In the process of implementing this technology, the students are expected to ascend to the tutor's perception, with the transfer of experience of sensory perception and intellectual understanding, intensifying the process of learning and self-development. This process is possible only with open perception of students, otherwise the tutor spontaneously implements technologies for restoring open perception of students through technologies of pedagogical creativity, pedagogical reflection, pedagogical intuition.

In the technologies of intensive visual activity distant training of bachelors-designers, the main methods are: the method of tutorial assistance, the method of pedagogical support, the method of implementing communication, the projects method, the media method master classes.

The ecological approach, in the context of our article, consists in organizing distant training with the environmental conformity technologies, bio-adequate tools, and the student's hemisphere development activation. Its implementation aims to concentrate the perception, attention and thinking of students directly on video material. Attention and perception have the following characteristics: depth, volume and speed, and when this 
principle is implemented, their volume increases, and the speed of perception and thinking becomes high, which corresponds to the signs of intensive learning. Understanding the ability of "perception" as a mobile phenomenon forces the tutor to introduce a new principle in learning - the principle of continuous expansion and deepening of the students' perception and to increase their own speed of methodological actions.

The empirical approach in distant training is based on the intellectual and sensory experience of the tutor's and student's personality, on a dynamic neoplasm in the form of the student's constant self-development. There are two development stages - the first is that the person perceives someone's knowledge and on the basis of it receives experience, this is the basis for all training. The next stage of development is that the person draws knowledge from his experience, and at this stage, the person creates the author's technology.

The existential approach in distant training arises in accordance with the new mental qualities of students who become existential, open, empathic. The main worldview task of students is to connect with their source of existence, the source of original creative power.

The action and relevance of the existential approach is easy to detect in the content of new professions in Russia, which will have appeared by 2030. So, in industry "education" is called a profession - a developer of tools for teaching states of consciousness, for teaching users productive states of consciousness - high concentration, relaxation, increased creative abilities. [3] With distant training, the best source of creative states of consciousness necessary for visual activity is the assistance of a tutor, which awakens the "hidden" creative processes of students, this is nature-friendly, like transmitting inspiration to students, activating their creative activity. [4] [5]

The method of cooperation in distant training is very important for the social forces' development. Cooperation is interpreted as a way of simultaneous development of the forces of both personal and social forces for the students and a tutor-tutor in distant training. The peculiarity of the method of cooperation in distant training is that the student's personality can join the forces of other students and the power of a tutor in the conference mode. A mobile mental field is created, in the space of which the creative tasks in the process of visual activity can be discussed and solved. Cooperation is a spiritual process, the main existential qualities of a person in it are openness, generosity, and they are the foundations of cognitive activity, increased interest, joy and love for the activity.

Many modern scientists - teachers and psychologists (A. M. Kushnir, I. S. Yakimanskaya, B. G. Ananiev, L. I. Bozhovich, A. I. Lipkina, etc.) are the adherents of personality-oriented learning, which the system of pedagogical assessment suggests starting from the process of changing a particular student. In other words, the resource approach should be a priority, based on the student's capabilities consideration.

\section{Model of tutorial assistance in distant training for the bachelor-designers}

In the works of Serikov G.N. the content of pedagogical assistance is defined as: "Pedagogical assistance to educating people in the assimilation of social experience means a special type of social influence on them, by presenting for learning in a special way systematized and interpreted in accordance with the socially accepted value guidelines the content of information about social experience" [6]. In the context of the aforesaid, we can derive the tutorial assistance definition in distant training: "Tutorial assistance in the passage of the educational route by the students in distant training of visual activity means promoting the students' integration in the electronic information educational environment, adaptation, sustainable self-development and successful self-realization in this environment"

The model of tutorial assistance in distant training has the following components: 
- purposeful, which is based on goals, objectives, we can say the social order of the society;

- basic, having its component content of visual activity in the context of the implemented areas' educational standards;

- event component, which is based on drawing up a block of tasks with the initial formation of an event as stimulation of the motivational and emotional sphere of students;

- operational content, including an educational resource, methods, methods, forms and means of assistance in distant training;

- the resultant - effective, the basis of which is the analysis and performance sections, ratings, fixing acquired knowledge, skills, mental increments and personality neoplasms.

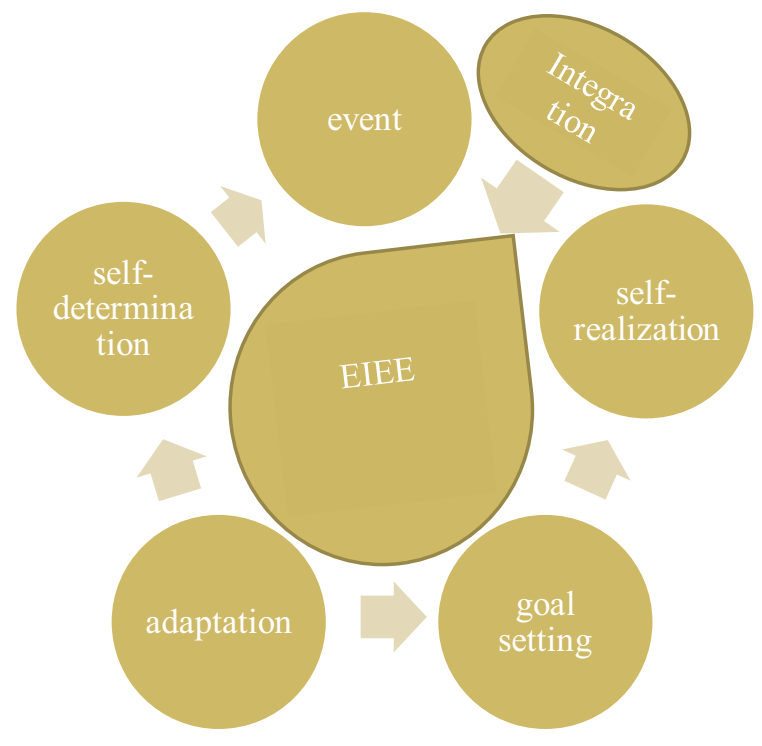

Fig. 1. Electronic information educational environment (EIEE).

The figure shows a model of tutor assistance to integrate students into the electronic information educational environment.

\section{Criteria for evaluating the products of visual activity of bachelor-designers}

The analysis of creative self-realization in distant training at the integrated course of fine art makes it possible to highlight its assessment. It is possible to determine the development level of the visual activity quality using diagnostics based on a students' visual activity homogeneous products quality comparative analysis created by them in a given time interval. These criteria will allow to assess the conformity degree of the visual activity products with its possible results. The acquisition of new knowledge through tutorial assistance in the distant training of bachelor-designers in the process of creative selfrealization, development of skills and improvement of skills are innovative and active for the students, appropriate criteria levels can be applied to them.

The rationale for the assessment criteria and the self-realization substantiation levels for the students in visual activity are its products. The criteria for evaluating the products of visual activity can be considered as dynamic artistic images, iso constructions, adequately reflecting the emotional-sensual sphere, neoplasms in all areas of personality development. 
The history, theory, methodology and practice of fine art outlined trends in evaluating the activity products as an integrity, outlined by the classical teachers and the teachers of various schools. By setting the goals and objectives of producing the activity products (compositional characteristics, completeness of iso construction, volume, shape, environment, texture, light, tone, color), the criteria for their assessment are determined.

In distant training, the evaluation criteria depend on the educational process meanings, on the total indicators of the students' achievement, which is determined by the teacher's attitude to the qualitative increment of the students 'activity products, taking into account the assessment of each task component. The integrity of the assessment lies in the unity of the image quality individual indicators in conjunction with the new indicators' integrative qualities. The existing standards play the role of a criterion for the visual activity stages' passage success by the students. The product of visual activity is evaluated by its uniqueness, originality, significance, the way of execution - by the divergence of thinking, by creativity.

For a dynamic assessment of an individual's creative development manifestation, it is important to consider the criteria on the basis of which it is possible to judge the manifest and potential creative possibilities. The discovery of "oneself" through the development of "self-processes" is a special act of self-realization, which is confirmed by the adequate embodiment of the artistic intentions in material works. The subjective experience of the creative process is transformed into a constant source of "scooping" of creative ideas and creates a need for material embodiment, the path to which was directed by the teacher tutor. The criteria for personal development are neoplasms that arise in the student's mind and provide the new ways of working and the forms of behavior. Personal growth indicators are the subjectivity manifestations. The inner world formation process for the students is determined by the content of their subjective experience of life and selfrealization.

The criteria for personal self-realization should be a balance between the potential capabilities of an individual and his real achievements, which take into account the attitude to the world, the meaning of the activity. The criteria for the creative development of bachelors-designers are the dynamic creative formations reflecting his creative activity quality.

By dynamic creative formations we understand the means of moving the personality of the students up through the designated stages of creative self-realization:

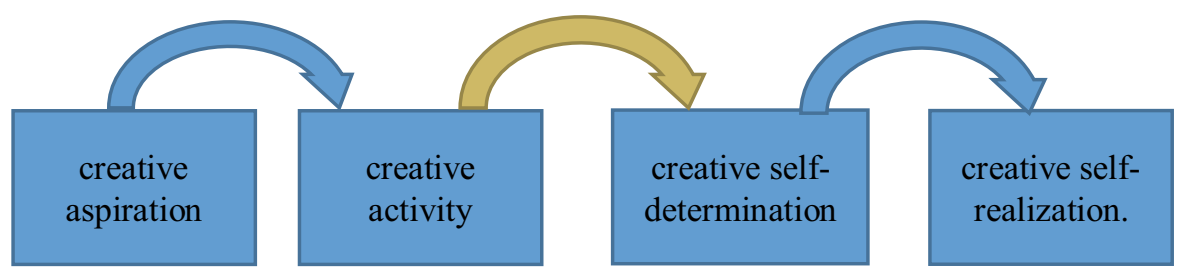

Fig. 2. The figure shows the dynamics of creative formations.

We proceed from the fact that a person is a subject of versatile active activity that transforms the world. According to B. G. Ananiev, it is a subject of knowledge, labor and communication. The pedagogical content of the concept has its own specifics based on the consideration of those components (properties, structures, processes) that become the subject of care, help and support of the pedagogically controlled process of development and self-development of a personality (Gorbunova M.A., Zaparin D.L., Bityanova M.A.) [7]. E.A. Yamburg writes about the importance of stabilization in creative processes: “... 
stabilization requires creativity, then, in turn, creativity requires stabilization. An endless, unsystematic pursuit of innovations can explode from the inside" [8].

Stabilization constantly requires ingenuity, the search for innovative solutions, that is, the creativity that any live-thinking teacher dreams of. In his reflections on the creativity phenomenon, its origins and meaning, Yamburg E. A. emphasizes that teachers have their own pragmatic interest, that in the depths of pedagogical consciousness "there is a hope to find the treasured golden key with which it will be possible to discover a method, method, technology expanded reproduction of talent" [8]. Creativity management is largely reduced to the scientific leadership (to manage stabilization and creative processes, it is necessary to have a pedagogical philosophy and development strategy to harmonize the pedagogical paradigms).

\section{Core ideas of tutoring technology}

During the experiment, the main ideas of the tutorial assistance technology in distant education of the visual activity bachelors-designers were revealed in the following provisions:

- application of technologies of targeted work with educational resource contents;

- broadcasting special technologies and techniques of visual activity;

- realization of creative potential is possible only in a favorable, professionally adapted educational environment;

- the adequacy of the student's internal state, the formation of the individuality spheres occurs through creative positive visual activity;

- effective combination of group and individual training;

- there is an increase in the level of adaptation, motivation and the expansion of the students' achievements scope, improving the quality of external communications;

- the formation of the students' formation process as the subjects of visual activity, coperformers and co-authors of the art and educational program.

The motivation of students should be considered as a system of formation of interest in learning, education of a responsible attitude to visual activity. For the development and improvement of the self-regulation sphere, it is necessary to design the transfer of students to higher levels of their skills development in analyzing life situations, awareness of their behavior, the formation of skills for an honest attitude towards themselves and other people.

\section{Summary}

The vector of tutorial assistance in distant training is directed towards the target priorities and interaction of the subjects of the educational process, its humane-oriented, democratic personality-forming system. In distant training, the trends of the triad in the system tutor (moderator) $\rightarrow$ subject of training (management) $\rightarrow$ subject of self-government (selfdevelopment) are logically justified. With this form of training, tutorial assistance is the most acceptable technology and a humane form of pedagogical interaction, creating the conditions for self-development and self-realization for the students. To implement distant training, the author's courses should be developed in the format of electronic text, video and audio courses, guidelines for laboratory work, textbooks, and presentations. In distance education of bachelors - designers, the most popular is the visual range of content, taking into account the specifics of teaching visual activity. Electronic educational resources in the format of video materials are relevant for the successful organization of distant training. For better assimilation of the material in media studios, it is necessary to create the video lectures on the fine art basics, demonstration films, media courses, videos with 
an algorithm for performing laboratory work in special disciplines. The presence of the above-mentioned multimedia educational content will contribute to the individualization and differentiation of distant training, the possibility of self-correction and self-control, modeling and forecasting of the final product. A methodically competent distribution of the graphic means of educational content will develop visual-figurative thinking, form a culture of cognitive activity, and increase the training effeciency.

\section{References}

1. National project "Education”, https://edu.gov.ru/national-project

2. T.M. Kovaleva, The main trends in the development of modern education: Materials of the international scientific-practical conference (ITOiP RAO, Moscow, 2002)

3. Atlas of New Professions, https://atlas100.ru/

4. O.D. Kartavtseva, Scientific foundations of existential pedagogy (monograph) (SFU, Rostov-on-Don, 2011)

5. O.D. Kartavtseva, Spiritual development of personality on the basis of self-realization of the essential forces in creativity (monograph) (SFedU, Rostov-on-Don, 2009)

6. G.N. Serikov, Pedagogy. Book 1: Object of Research (Humanitarian Publishing Center VLADOS Moscow, 2005)

7. M.R. Bityanova, Social Psychology (PeterPress, 2007)

8. E.A. Yamburg, Adaptive School Development Management (PERSE press, Moscow, 2004)

9. D.B. Epiphany, Psychology of creative abilities (Academy, Moscow, 2002)

10. O.S. Grebenyuk, Pedagogy of individuality (ACADEMIA, 2006)

11. L.S. Vygotsky, Pedagogical Psychology (ACT, Astrel, Lux, Moscow, 2005)

12. S.V. Maklakov, BPwin and ERwin. CASE-tools for the development of information systems (DIALOG-MEPhI, Moscow, 1999)

13. Yu.B. Borev, Aesthetics (Rusich, Smolensk, 1997)

14. I.V. Abakumova, M.V. Godunov, D.A. Gurtskaya, Bulletin of the Udmurt University. Philosophy. Psychology. Pedagogy 29(4) (2019) doi: https://doi.org/10.35634/24129550-2019-29-4-413-420

15. N.A. Brykova, A.N. Sbytova, Y.V. Gorgorova, IOP Conference Series: Materials Science and Engineering 698(3) (2019) https://iopscience.iop.org/article/10.1088/1757899X/698/3/033026

16. N.Y. Zakharova, I.V. Protopopova, V.A. Shepilova, Yu.G. Likhovid, IOP Conference Series: Materials Science and Engineering 698(3) (2019) https://doi.org/10.1088/1757899X/698/3/033018

17. N.Y. Zakharova, I.V. Protopopova, Architectural and artistic activity as a condition of the development of the existential sphere of students Materials Science Forum (2018) https://www.scopus.com/authid/detail.uri?authorId=57204524915

18. N.Yu. Zakharova, I.M. Vlasova, I.V. Protopopova, R.L. Lukyanov, IOP Conference Series: Materials Science and Engineering 698(3) https://doi.org/10.1088/1757899X/698/3/033013 